4. ALGUNAS REFLEXIONES JURIDICOCONSTITUCIONALES SOBRE EL DERECHO A LA REPRODUCCIÓN HUMANA Y LAS NUEVAS TÉCNICAS DE REPRODUCCIÓN ASISTIDA 
I. INTRODUCCION.-II. EL DERECHO A LA REPRODUCCION HUMANA.-1. Derecho a la reproducción: la interpretación más favorable a la libertad. 2. El derecho a la reproducción y el principio de igualdad. 2.1. La igualdad entre los sexos y las nuevas técnicas de reproducción asistida. 2.2. Esterilidad y reproducción asistida. III. REPRODUCCION ASISTIDA Y PLURALIDAD DE SUJETOS CONCURRENTES.-1. La realidad plural. 2. Reconocimiento juridico de la pluralidad de sujetos intervinientes. 3. Reproducción asistida y donación de gametos. 3.1. Voluntariedad. 3.2. Donación: acto personalísimo. 3.3. El secreto de la donación. 3.4. El carácter comercial de la donación de gametos. 3.5. La revocabilidad de la donación de gametos. IV. LA GESTACION DE SUSTITUCION: LAS MADRES DE ALQUILER.-1. Concepto. 2. La maternidad por contrato. V. LA GESTACION ASISTIDA EN LA MUJER SOLA.-VI. FINAL. 


\section{ALGUNAS REFLEXIONES JURÍDICO-CONSTITUCIONALES SOBRE EL DERECHO A LA REPRODUCCIÓN HUMANA Y LAS NUEVAS TÉCNICAS DE REPRODUCCIÓN ASISTIDA *}

\section{INTRODUCCIÓN}

El viejo principio romano mater semper certa est ha perdido en la actualidad su intangibilidad. Durante miles de años, la reproducción humana había sido un proceso inmutable en su forma y a la vez indefinidamente repetido. Esta actividad humana, inalterable durante tanto tiempo, ha sido alcanzada por un alud de novedosas posibilidades que la han transformado profundamente.

Los modernos avances científicos en el campo de la reproducción húmana han modificado absolutamente conceptos tan antiguos como el propio hombre, tales como paternidad, maternidad, filiación y, en general, han afectado a la práctica totalidad de las llamadas relaciones familiares.

A pesar de que frecuentemente hablamos de técnicas nuevas para referirnos a las variantes de reproducción humana (así lo haremos también en este trabajo), lo cierto es que este tipo de investigaciones se producian ya en el siglo XVIII ${ }^{1}$, aunque, en realidad, es a partir de la mitad del presente siglo cuando los estudios se hacen más frecuentes, de mayor intensidad y se consiguen resultados más espectaculares.

Estas nuevas posibilidades de reproducción requieren, como ya autorizadas voces han manifestado en distintos paises, una regulación que no tienda tanto a reprimirlas como a garantizar un uso adecuado de ellas. Esa es la misión y el gran reto del Derecho. No lamentamos nosotros, como

* Este trabajo proviene y básicamente se encuentra contenido en mi Tesis Doctoral, redactada en 1986, juzgada, en junio de 1987, en la Universidad Nacional de Educación a Distancia y que, con el título «El Derecho constitucional relativo al matrimonio y a la familia: los artículos 32 y 39 de la Constitución española de 1978", me permitió alcanzar, con la máxima calificación, el Grado de Doctor en Derecho.

En el momento de su redacción no se habian presentado las Proposiciones de Ley a las que se hace referencia en este trabajo, algunos de cuyos criterios se corresponden con lo que ya mantenía en mi trabajo original y se reitera en el presente; en otros casos, sin embargo, discrepaba entonces y discrepo ahora de las opiniones más comunmente sostenidas en puntos concretos de la regulación más aconsejable de las nuevas formas de reproducción asistida.

En cualquier caso, me congratulo enormemente de que, al menos en algunos puntos, el intento de regulación de estas nuevas formas de reproducción humana en nuestro país coincidan con las opiniones que manifestaba en mi trabajo de Tesis Doctoral como más coherentes y ajustadas a las coordenadas de una sociedad democrática.

.1 Informe de la Comisión especial de estudio de la fecundación in vitro y de la inseminación artificial humanas. Congreso de los Diputados, Madrid, 1987, pág. 31. 
tantas veces puede oírse y leerse, que el Derecho vaya detrás de la realidad social. Sólo yendo detrás podrá el Derecho recoger la voluntad general, sólo palpando esa realidad, los problemas y el sentir de los que serán receptores de las normas podrá el Derecho intentar acercarse a lo que debe ser su fin: regular la sociedad tal y como sea querida por aquellos que la componen. Ninguna otra interpretación seria válida en un sistema democrático. Ninguna otra es legítima en un Estado constitucional democrático, y en él, la Constitución como Norma suprema manifiesta las coordenadas que vertebran el orden social y la jerarquía de valores asumida.

En nuestro pais, desde 1978, cualquier análisis sobre nuestro Ordenamiento jurídico debe hacerse de conformidad con los principios constitucionales, ya expresos sobre la materia, ya inferidos de aquellos otros principios y valores que mantienen el sistema constitucional y por ende el modelo democrático actual, si es que, en el texto fundamental, como es el caso que nos ocupa, no existe una regulación concreta sobre la materia de estudio.

Actualmente el interés sobre estas prácticas de reproducción asistida está creciendo entre nosotros. En este año han sido ya dos las Proposiciones de Ley presentadas en el Congreso de los Diputados sobre técnicas de reproducción asistida y sobre donación y utilización de embriones $y$ fetos humanos ${ }^{2}$. Hay que esperar que en breve contemos con una regulación sobre estas cuestiones, y que en ella se aborden los problemas con respeto a los derechos y libertades fundamentales constitucionalmente reconocidos y sin excesivo temor a transformar las relaciones familiares tradicionales si con ello se amplía y profundiza en la libertad individual y en el respeto de los derechos de las personas.

Los problemas que se plantean acerca de las nuevas formas de reproducción humana son muchos. Ello nos obliga, en este breve trabajo, a abordar sólo algunos aspectos que consideramos de interés, especialmente bajo un punto de vista jurídico-constitucional.

2 Proposición de Ley del Grupo Parlamentario Socialista del Congreso sobre «Técnicas de reproducción asistida». Boletín Oficial de las Cortes Generales -Congreso de los Diputados--, núm. 74-1 de 9 de mayo de 1987.

- Proposición de Ley del Grupo Parlamentario Socialista del Congreso sobre «Donación y utilización de embriones y fetos humanos o de sus células, tejidos u órganos", Boletín Oficial de las Cortes Generales - Congreso de los Diputados- núm. 73-I de 9 de mayo de 1987. La tramitación de ambas Proposiciones ha sido acordada por el Congreso de los Diputados con fecha 16 de diciembre de 1987. 


\section{EL DERECHO A LA REPRODUCCIÓN HUMANA}

La Constitución española trata de la madre en su artículo 39,2 y de los padres, abarcando a ambos sexos, en el apartado 3 del mismo artículo 39. A la primera se la protege integralmente; a los segundos se les exige que presten asistencia de todo orden a sus hijos ${ }^{3}$. Pero no reconoce nuestra Constitución un derecho expreso a tener hijos. Ello no es estrictamente necesario: otros valores y principios constitucionales suplen perfectamente esta ausencia, como intentaremos exponer enseguida.

En el Derecho comparado, en la misma línea seguida por nuestro texto constitucional, encontramos escasas referencias a la regulación constitucional del derecho a procrear ${ }^{4}$. Más preocupación, en cambio, ha despertado esta cuestión en el ámbito internacional especialmente en la última década ${ }^{5}$.

Los logros obtenidos en el campo de la inseminación artificial, la fecundación in vitro, la transferencia de embriones y demás técnicas de reproducción asistida ${ }^{6}$ nos permiten, acaso nos obliguen, a plantearnos la cuestión previa de la existencia o no de un derecho a la procreación y, en su caso, la de su carácter absoluto o limitado y, si fuera lo segundo, cuáles serian sus límites.

3 Los apartados 2 y 3 del artículo 39 de la Constitución española dicen:

"2. Los poderes públicos aseguran, asimismo, la protección integral de los hijos, iguales éstos ante la ley con independencia de su filiación, y de las madres, cualesquiera que sea su estado civil. La ley posibilitará la investigación de la paternidad.

3. Los padres deben prestar asistencia de todo orden a los hijos habidos dentro o fuera del matrimonio, durante su minoría de edad y en los demás casos en que legalmente proceda."

4 De los posibles ejemplos el más significativo es, sin duda, la redacción dada al artículo 191 de la Constitución yugoslava que dice: «Es derecho de la persona resolver libremente sobre tener o no tener hijos. Este derecho únicamente podrá limitarse para proteger la salud."

5 Hay que citar en este punto los trabajos del Consejo de Europa, en especial:

- Rapport sobre inseminación artificial humana de 18-XII-81. Documento núm. 4.776/81.

- Recomendación de la Asamblea Parlamentaria relativa a la ingeniería genérica. Documento núm. 934/82.

Recomendación, Documento núm. 1.046/86.

- La inseminación artificial consiste en la introducción del semen masculino, por procedimientos mecánicos no naturales, en los órganos genitales femeninos; la fecundación posterior, en su caso, se produce de forma natural. La fecundación in vitro o ectogénica (fecundación en tubo de ensayo) supone que la unión de los gametos se produce fuera de los órganos genitales femeninos, en tubo de ensayo, del cual el ya embrión es trasladado a un útero femenino para continuar la gestación que se inicio en el laboratorio. 


\section{Derecho a la reproducción: la interpretación más favorable a la libertad}

Si bien, como hemos dicho, nuestro texto constitucional no reconoce de forma expresa un derecho a la reproducción humana, tal derecho deriva, en nuestra opinión, directamente del reconocimiento de la libertad como valor superior del Ordenamiento jurídico (art. 1.1 de la Constitución) y de la dignidad de la persona humana como expresión del reconocimiento de sus derechos inherentes y del libre desarrollo de su personalidad (art. 10.1 de la Constitución) en tanto piezas esenciales del sistema constitucional democrático. En democracia la libertad vertebra el orden jurídico y social. En democracia los límites a la libertad no se suponen sino que deben encontrarse expresamente recogidos en la Norma suprema o derivarse de los principios que la informan. No cabe una interpretación restrictiva en este tema. La libertad es el contexto único en el que la democracia puede darse, por ese motivo su extensión debe ser tan amplia, por definición, como sea posible sin vulnerar el resto de los principios y valores del propio sistema democrático.

El Tribunal Constitucional, por su parte, ha afirmado en varias ocasiones que, en materia de derechos y libertades, los límites o restricciones deben encontrarse en la propia Constitución y basarse en el respeto a los derechos de los demás $y$ al de otros bienes constitucionalmente protegidos ${ }^{7}$. No puede, por tanto, sacrificarse la libertad a todo fin social cualquiera que éste sea. El principio interpretativo es, como hemos apuntado, el contrario: extender el ámbito de la libertad hasta donde sea posible sin vulnerar otros valores y principios constitucionalmente reconocidos y, colisionando aquéllos con cualquiera de éstos, interpretar de conformidad con la amplitud del reconocimiento y tutela con que la propia Constitución los recoja. En nuestra opinión la libertad, como continente del sistema democrático, posee un lugar preeminente en esta jerarquia.

Tradicionalmente suele distinguirse entre los llamados derechos de libertad y derechos de prestación. Si los segundos implican una actividad positiva de los poderes públicos, los primeros consisten en el reconocimiento de una esfera personal del individuo, dentro de la cual el sujeto puede actuar con plena autonomia, en cuyo ámbito el sujeto es soberano. En este último supuesto, los poderes públicos tienen por misión la no injerencia y la tutela necesaria para evitar perturbaciones de terceros de ese ámbito personal de cada sujeto. El reconocimiento de ese espacio vital del individuo nos permite, por ejemplo, hablar de dignidad de la persona y de 
su libre desarrollo personal, conceptos que sólo pueden explicarse a partir de tal reconocimiento.

El reconocimiento de la libertad, como valor superior del Ordenamiento jurídico, en el artículo 1.1 de nuestro texto constitucional tiene a mi juicio, un valor juridico directo. Su carácter de valor, según la terminología constitucional, no sólo hacen de él un principio informador sino que también supone el reconocimiento juridico de la libertad intrínseca del hombre. Ello se traduce en la necesidad de que el Ordenamiento jurídico determine expresamente los límites al ejercicio de esa libertad humana, fuera de los cuales, el hombre puede actuar libremente. No se trata tanto de que la ley permita actuar al individuo sino que sólo la ley pueda determinar los límites de dicha actuación. No se trata tanto, pues, de que el individuo haga lo que la ley permita como de que pueda hacer todo aquello que la ley expresamente no prohiba, constituyendo, en este caso, un límite legal y legitimo de su libertad.

El derecho a la reproducción no es, en este sentido, un derecho constitucional, pues no se encuentra inserto expresamente en el texto fundamental, pero si es un derecho con fundamento constitucional. Fundamento que no es otro que el reconocimiento positivo, constitucional, de la libertad.

Es esta interpretación, que estimamos correcta, la que nos permite afirmar que, en un sistema democrático, existe un derecho a la reproducción de toda persona, derivado del ejercicio de su libertad y que es expresión, al mismo tiempo, de su dignidad humana y del libre desarrollo de su personalidad (arts. 1.1 y 10.1 de la Constitución), derecho que no puede ser restringido arbitrariamente o sin justificación suficiente por los poderes públicos.

El derecho a la procreación es, por tanto, una realidad deducible con facilidad del reconocimiento de otros principios constitucionales, aunque su sola existencia no determina su extensión. El sistema democrático es una construcción de equilibrios, de ponderación y de tolerancia. La democracia no debe contener tanto en sí misma una moral como un criterio regulador que actúa excluyendo otras morales incompatibles con sus principios. Es el sistema de la definición por exclusión. Es el sistema más de lo que no es que de lo que es. Qué otra cosa es el progreso sino el saber excluir lo que las cosas no son.

Si basamos el derecho a la procreación en la libertad y en la dignidad de la persona como principios constitucionalmente reconocidos debemos aceptar que tal derecho a la reproducción no tiene por qué ser absoluto. Carecería de sentido jurídico que el derecho a la procreación fuera absoluto y no lo fueran aquellos de los que deriva y en los que tiene su origen.

Una vez más diremos, siguiendo la jurisprudencia del Tribunal Constitucional en materia de interpretación de derechos y libertades, que la extensión de los derechos y libertades, en este caso de la libertad y de la 
dignidad humana de las que deriva el derecho a la reproducción, debe alcanzar el máximo posible sin llegar a vulnerar otros principios constitucionales o bienes constitucionalmente protegidos. Los limites no serán más que aquellos que constituyan medidas necesarias en una sociedad democrática, como establece en varios de sus preceptos el Convenio Europeo de Derechos Humanos, criterio que se ha dejado sentir en la jurisprudencia del Tribunal Europeo de Derechos Humanos ${ }^{8}$.

¿Hay pues límites al derecho a reproducirse? Creemos que sí. Pero estos límites no son otros que los derivados del ejercicio de la propia libertad y de la libertad de los demás; del ejercicio de los propios derechos y del respeto a los derechos de los demás. $Y$ es que, como ya dijimos, en un Estado constitucional democrático la libertad es la regla y la restricción de esa libertad la excepción.

\section{El derecho a la reproducción y el principio de igualdad}

La igualdad queda reconocida en nuestra Constitución como valor y también como principio jurídico (arts. 1.1 y 14 de la Constitución). Pero, además, es bien cierto que este principio no tiene carácter autónomo. No podemos afirmar de él to mismo que decíamos de la libertad como posibilidad de hacer todo aquello que no se encuentre prohibido o atente a los derechos de los demás 0 a otros bienes constitucionalmente protegidos. La igualdad es un derecho relacional como afirma A. TORRES DEL MORAL ${ }^{~}$. La igualdad se aplica y se explica siempre en relación con otro valor, bien o derecho al que informa y del que dice en qué términos debe ser reconocido y aplicado.

El Tribunal Europeo de Derechos Humanos ha decantado una interesante doctrina sobre el particular que, básicamente, consiste en la consideración del principio de igualdad (art. 14 del Convenio de Roma) como carente de carácter autónomo y de existencia independiente. Es complemento de las demás disposiciones normativas del Convenio ${ }^{10}$. Algo parecido puede predicarse del tambien artículo 14 de nuestra Constitución - principio de igualdad-y del valor igualdad contenido en el artículo 1.1. Nuestro Tribunal Constitucional ha dado entrada a una doctrina semejante ${ }^{11}$ que declara el valor relacional del principio de igualdad.

- SSTEDH de 25-III-1983, caso Silver y otros; de 7-XII-1976, caso Handyse; de 6-IX-78, caso Klass y otros, etc.

9 A. Torres del Moral, Principios de Derecho constitucional español. Vol. 1 Madrid, 1985, pág. 12.

${ }_{10}$ SSTEDH de 23-VII-1968; 27-X-1975; 13-III-1978; 22-X-1981 entre otras.

" Así, por ejemplo, SSTC 76/1983, de 5 de agosto y 103/1983, de 22 de noviembre. 
Igualdad no supone, como es sabido, trato idéntico de cualquier situación, aunque sí trato igual para situaciones iguales. La diferencia, jurisprudencialmente establecida por el Tribunal Constitucional, entre desigualdad justificada y discriminación prohibida por la Constitución se encuentra básicamente en que tal diferencia no responda a criterios de justificación razonable ${ }^{12}$.

En el problema que tratamos aparecen dos vertientes conflictivas respecto al principio de igualdad. La primera se refiere a si las nuevas técnicas de reproducción asistida deben aplicarse, en lícito ejercicio del derecho a la reproducción, a hombres y mujeres, la segunda, consiste en si sólo deben aplicarse en determinadas circunstancias personales (por ejemplo, a personas unidas en matrimonio), o deben aplicarse a quien lo solicite y reúna los requisitos generales que se establezcan.

\subsection{La igualdad entre los sexos y las nuevas técnicas de reproducción asistida}

La discriminación por razón de sexo está expresamente prohibida por nuestro texto constitucional (art. 14). Determinadas las circunstancias o condiciones en que pudieran aplicarse las técnicas de reproducción asistida, tanto tendrían derecho a solicitarlas individualmente los hombres como las mujeres. Es obvio, por otra parte, que tratándose de parejas debe darse una concurrencia de voluntades y deben ser ambos sujetos los que soliciten la aplicación de estos métodos reproductivos. Estas afirmaciones, sin embargo, requieren ciertas matizaciones.

Aunque una interpretación que creemos correcta del principio de igualdad nos lleve a afirmar que tanto los hombres como las mujeres tendrían derecho a beneficiarse de los avances en materia de reproducción asistida no podemos ocultarnos que, hasta ahora, la ciencia ha hecho posible más la solución de las demandas de las mujeres que las de los hombres cuando unas y otros actúan individualmente. Ello se debe a que si bien ambos, hombres y mujeres, pueden constituirse en donantes de sus propios ovocitos (esperma y óvulos), el hombre precisa además de la colaboración de una mujer para que lleve a término la gestación. Es decir, la mujer puede, en gran número de casos, conseguir una gestación completa y el consiguiente nacimiento de un hijo con la sola aportación del semen de un donante. En igualdad de circunstancias el hombre no puede completar su derecho a reproducirse salvo con la concurrencia de una mujer que geste al hijo.

Esta diferencia es, de momento, esencial y da al derecho de los hombres a reproducirse unas connotaciones distintas a su paralelo feme-

12 STC 42/1982, de 5 de julio, en relación con la 73/1984, de 27 de junio. 
nino. Si bien tal derecho a la reproducción le corresponde por igual a hombres y mujeres, aquéllos pueden tener más dificultades para realizarlo por la necesidad de contar con un útero gestador. No es, sin embargo, su derecho de distinta naturaleza. Antes al contrario: los hombres se encontrarian en un supuesto similar al de las mujeres que no pueden llevar a cabo el proceso gestativo y que ha dado origen a la aparición de las llamadas madres de alquiler.

Podríamos, en un intento de mejorar la situación de los hombres respecto al ejercicio individual de su derecho a reproducirse, defender que a éstos debería proveérseles de la posibilidad de alquilar úteros para gestar hijos a partir de su propio esperma. Por lo que diremos en el apartado dedicado a las madres de alquiler, al que remitimos, estamos en disconformidad con tal práctica.

Las dificultades que tienen en la actualidad los hombres para acceder en solitario a la paternidad, derivadas principalmente de la imposibilidad, por el momento, de concluir una gestación en laboratorio y precisar por ello de la concurrencia de una mujer que geste al hijo, no disminuye ni desvirtúa su derecho a la reproducción, como ya hemos dicho. Lo importante es, por tanto, concluir que tal derecho es hoy por hoy más una expectativa que una realidad. Mas, si se consiguiera llevar a término una gestación con independencia del útero femenino nada cabría objetar a que los hombres solicitaran la gestación de un hijo por estos medios a partir de su propia aportación genética, si tal posibilidad estuviera reconocida a las mujeres.

\subsection{Esterilidad y reproducción asistida}

Actualmente la tendencia más general es que estas técnicas se apliquen exclusivamente 0 , al menos, de forma preferente a los supuestos de esterilidad, pero la demanda se ampliará muy pronto si no es ya una realidad fácilmente constatable. El aumento del número de mujeres que desean acceder a la maternidad en solitario es hoy una realidad incontestable en las modernas sociedades de la que la nuestra no es excepción. Opino, sin embargo, que también en el futuro los hombres podrian demandar la paternidad en solitario, según lo que hemos expuesto en el apartado anterior.

Las nuevas formas de reproducción asistida deberian dar respuesta también a estas expectativas y al deseo consciente y voluntario de reproducción sin pareja. Ello se debe a la lícita decisión de no contraer un vínculo jurídico o de hecho con el único fin de reproducirse.

La pareja, aun siendo una realidad muy extendida en la sociedad, coexiste hoy como otras formas vivenciales, con otras realidades igual- 
mente válidas a nuestro juicio, como es la existencia de sujetos individuales o la de parejas no estables ${ }^{13}$ aunque continuadas en el tiempo.

Ante esta pluralidad de opciones vivenciales la negativa a facilitar a las mujeres no estériles su acceso a la maternidad a partir de donantes de esperma, siendo ya esto posible y estando aceptado, supone obligarlas a unirse más o menos formalmente en pareja para tener un hijo o bien a no tener ese hijo si no consiguen una pareja más o menos estable. Lo que nos parece un doble castigo absolutamente innecesario. Estamos de acuerdo en que los nuevos sujetos deben nacer en un contexto que les facilite su desarrollo y su felicidad y en el que cuenten con el afecto del o de los que lo engendraron o de los que asuman las obligaciones socializadoras respecto de él. Por ello creo más conveniente el nacimiento de un nuevo sujeto con un solo progenitor consciente y voluntario que con dos progenitores en desacuerdo. La aceptación de la pluralidad implica no sólo la tolerancia de situaciones distintas sino también su valoración en similares términos:

Según lo que venimos diciendo, aceptar que las mujeres puedan tener acceso a las nuevas formas de reproducción asistida, mediante donante, sin ser estériles, supone una diferenciación con respecto a las posibilidades con que cuentan los hombres en este mismo campo. No creemos, sin embargo, que ello suponga ningún tipo de discriminación prohibida constitucionalmente, pues no se vulnera la ley constitucional por no hacer lo imposible. Debemos tener en cuenta, por otro lado, que las nuevas formas de reproducción asistida no pueden hacer nada por el hombre estéril, ya que en este caso no hay medio alguno de conseguir que el sujeto estéril genere por sí mismo (nos referimos, obviamente, a la esterilidad biológica absoluta, que es la que impide la generación). La relación del hombre con su prole se identifica, en sentido biológico, con la aportación de la carga genética que contienen los gametos. Si éstos no existen o no son aptos para la generación no hay medio alguno de sustituirlos. La mujer dispone de una mayor gama de posibilidades $y$, en última instancia y aun con óvulo donado, puede gestar al hijo y mantener con él esta unión biológica. El viejo proverbio que afirmaba que madre no hay más que una ha devenido biológicamente incierto. Madres puede haber varias, pues es su aportación a la creación de un nuevo ser la única que puede dividirse. Realmente, padre sí que no hay más que uno, pues el hombre o es apto para la generación o no lo es.

13 Toda vez que la expresión pareja estable viene significando la existencia de una pareja no casada aunque con una realidad vivencial semejante, podemos definir como pareja no estable aunque continuada a aquella que posee una realidad vivencial discontinua. 


\section{REPRODUCCIÓN ASISTIDA Y PLURALIDAD DE SUJETOS CONCURRENTES}

\section{La realidad plural}

Lo primero que se evidencia cuando se aborda el estudio de las nuevas técnicas de reproducción asistida es que en ellas pueden intervenir, en sentido biológico o genético, varios sujetos femeninos y un solo sujeto masculino. En principio nada impide que el recién nacido, mediante la concurrencia de varias mujeres, tengan, legalmente, varias madres. Si los términos padre y madre han sido utilizados tradicionalmente (salvo en las relaciones adoptivas y alguna de similar carácter), para designar a aquellos que, a partir de sus propios elementos biológicos, generaban un nuevo ser, en la actualidad, a los partícipes que aportan algún elemento biológico al proceso generador debería, al menos, reconocérseles dicha aportación. Esta postura representaría la aceptación de una realidad humana, biológica si queremos, pero el Derecho, apegado a la configuración que ha servido durante miles de años a la reproducción más o menos ordenada de la especie, desconoce gran parte de esa realidad y sigue configurando las relaciones de filiación de espaldas a ella.

Esto es lo que se pretende, en nuestra opinión, cuando se intenta ocultar la realidad de este tipo de prácticas y hacer aparecer al hijo nacido como un producto ajeno a ellas. Como si su generación se hubiera producido por medios naturales, sin intervención científica. En realidad, lo que se pretende es que la generación del nuevo ser parezca producida dentro de un orden tradicional. Durante las sesiones celebradas por el Grupo de Trabajo constituido en la Dirección General de los Registros y del Notariado ${ }^{14}$, «se creyó oportuno sentar que lo deseable para el legislador es que el hijo nazca en el seno de una familia, y engendrado dentro del matrimonio". Afirmación discutible a partir de la Constitución de 1978 y, además, de difícil comprensión pues no se entiende muy bien cómo la existencia de un contrato civil de matrimonio puede favorecer el crecimiento y desarrollo del hijo hasta el punto de que se afirma a continuación que «estas condiciones son las que mejor facilitan el desarrollo de la personalidad del hijo» ${ }^{15}$. ¿No se olvida, una vez más, que, a partir de la vigencia de la Constitución, todos los hijos son iguales ante la ley? ¿Por qué va a desarrollarse mejor un hijo matrimonial que el no matrimonial? ¿Cuáles son las razones que permiten afirmar que el contrato civil de matrimonio posea por sí tales virtudes de desarrollo personal?

14 "Problemas civiles que plantea la inseminación artificial y la fecundación in vitro". Ministerio de Justicia, Secretaría General Técnica. Madrid, 1986, pág. 9.

15 "Problemas civiles que plantea la inseminación artificial y la fecundación in vitro". Ministerio de Justicia, Secretaria General Técnica, ob. cit., pág. 9. 
Parecida línea argumental parece haber informado algunos artículos de la Proposición de Ley sobre técnicas de reproducción asistida, pendiente de tramitación, presentada en el Congreso de los Diputados ${ }^{16}$, así, por ejemplo, cuando se regula el secreto en torno a la identidad de los posibles donantes, o cuando se trata de la esterilidad de los receptores de estas técnicas de reproducción asistida 0 , también, cuando se dispone el mismo secreto en torno a la inscripción de las circunstancias que concurrieron a la generación de los así nacidos.

El desarrollo equilibrado de los nuevos individuos depende, en nuestra opinión, de que encuentren en la sociedad un amplio margen de aceptación de distintas situaciones vivenciales para que, cualquiera que sea la suya, no se encuentren rechazados, marginados ni diferenciados. El equilibrio humano se basa, en gran parte, en la aceptación que se recibe del contexto social y humano en el que se encuentra inserto el sujeto. Las dificultades en el desarrollo de muchos niños hay que hallarla, sin ignorar otros factores, en una sociedad que los estigmatiza por razón de su nacimiento, a pesar de las múltiples declaraciones de respeto al principio de igualdad. La aceptación de más modelos de reproducción, de más formas de vida, dentro del respeto a los principios básicos de toda sociedad, permitiria, sin duda, un mejor desarrollo de los hijos.

\section{Reconocimiento jurídico de la pluralidad de sujetos intervinientes}

Puesto que, en los procesos de los que tratamos, la intervención de varias mujeres es común denominador en la mayoría de sus modalidades, debemos preguntarnos ahora si el Derecho debe reconocer esta pluralidad o, por el contrario, silenciarla y aceptar la ficción de que figuren exclusivamente como padres los que reconozcan al hijo juridicamente; esto último supone desconocer el valor jurídico de la aportación de los donantes de esperma o de ovocitos, o la de los sujetos que intervengan en una función que dentro del proceso concreto, se considere instrumental, por ejemplo, el caso de las madres de alquiler, del que trataremos en otro apartado de este trabajo.

Llegado este punto debemos hacer ciertas precisiones terminológicas que consideramos de interés. Si bien los conceptos de maternidad y paternidad han hecho siempre referencia y asi ha sido aceptado también por el Derecho, a los sujetos que habían generado a partir de su propia aportación biológica, nuevos individuos, alguna excepción siempre ha existido, por ejemplo, el instituto de la adopción. Con todo, los supuestos eran

16 Art. 2.5 de la Proposición de Ley núm. 122/000062 de Técnicas de reproducción asistida. 
tan escasos que la identificación de los padres con los generadores biológicos era prácticamente universal. Esta concepción, como veremos, tiene importancia a la hora de determinar la necesidad o no del reconocimiento jurídico de los concurrentes a un proceso generador.

A pesar de esta práctica universalidad de los conceptos de padre y madre, referida a los aspectos biológicos, como saben bien los estudiosos de las relaciones familiares muy frecuentemente se ha podido distinguir también entre maternidad/paternidad biológica y maternidad/paternidad sociológica o legal. Esta última se refería a la función de asistencia, educación y socialización del niño. Así, podriamos distinguir, en la actualidad, los siguientes supuestos:

\section{a) Maternidad:}

1) Maternidad plena, que es la que, junto a la relación biológica única de una mujer con su hijo, se une el haz de derechos y obligaciones que implica el reconocimiento jurídico de la generación.

2) Maternidad genética o gestativa parcial, en el supuesto de que la aportación de la mujer que después asume legalmente la condición de madre no haya sido única, existiendo, por tanto, la concurrencia de la aportación de otra u otras mujeres al nacimiento del niño.

3) Maternidad legal, que es aquella en la que la mujer asume los derechos y obligaciones respecto al nacido sin que existan entre ellos lazos biológicos.

b) Paternidad:

1) Paternidad plena, cuando el hombre aporta su carga genética y asume, además, los derechos y obligaciones del reconocimiento como padre.

2) Paternidad genética. Cuando aporta el esperma pero no asume los derechos y obligaciones derivadas de la generación.

3) Paternidad legal, en el caso de que el varón sólo pueda asumir jurídicamente el nacimiento por no haber contribuido biológicamente al nacimiento. 
No existe, en el caso del hombre, una paternidad parcial por imposibilidad de dividir su aportación biológica. Por otro lado, exceptuamos de esta clasificación los supuestos de abandono del hijo, es decir, la situación de un hombre o de una mujer que, tras engendrar biológicamente al hijo, no asumen los derechos y obligaciones respecto a él, sin que se trate de donantes, sobre los que nos ocuparemos después.

Pues bien, respecto a estas posibilidades, sobre todo en cuanto a la situación de las mujeres, parece que, en principio, los poderes públicos tienden a negar el reconocimiento jurídico a una pluralidad de sujetos intervinientes, asignando los derechos y obligaciones respecto al hijo a una pareja o sujeto concreto, a los que, según los casos, se denomina con exclusividad padre y/o madre.

En nuestra opinión esta postura no es correcta. La exclusión del reconocimiento juridico de la pluralidad de sujetos concurrentes a este tipo de nacimientos no cambia la realidad. La pluralidad ha existido. Sin duda el Derecho quiere con ello proteger al hijo y también a los que figurarán como padres y, quizá, también al donante, pero no creemos que el secreto lo consiga.

Antes de continuar debemos hacer una puntualización. El reconocimiento jurídico de una realidad no implica necesariamente la asignación de derechos y obligaciones a sujetos concretos. En ocasiones al Derecho debe bastarle con que se reconozca una situación, que conste jurídicamente.

Este podría ser el caso que nos ocupa. En el deseo de ejercer el derecho a la reproducción existe un acto resolutivo de la voluntad. Sin duda, los sujetos que se encuentran en este supuesto deben asumir las obligaciones derivadas de la procreación, ya sea natural o asistida. $Y$, consecuentemente, también deben corresponderles los derechos inherentes a tal situación.

La donación como acto voluntario y de carácter personalísimo, como veremos enseguida, debe ser decidida libremente por el sujeto. Quien no se encuentra en condiciones de asumir sus consecuencias debe abstenerse de llevarla a cabo. El reconocimiento jurídico de la existencia de donantes no perjudicaría a éstos, ya que, como dijimos, no tiene por qué ir acompañada de una serie de responsabilidades y obligaciones respecto al nacido. Pero la donación de gametos no puede compararse a ninguna otra donación, ya que sólo a partir de esta aportación genética surge un nuevo individuo. No puede hablarse en estos casos de donación en un sentido general, como si el elemento donado contribuyera al mantenimiento de un ser (como es el caso de la donación de órganos) y no, como es en realidad, a la creación de un ser distinto. Los donantes generan o contribuyen a la generación de nuevo individuo. Algo más diremos acerca de este punto, al tratar del secreto en la donación. Baste ahora señalar que, a nuestro juicio la ocultación de la identidad de los donantes conculca seriamente los de- 
rechos de los hijos nacidos mediante estas técnicas de reproducción asistida, como trataremos de exponer en su momento sin que se vea, en principio, cuál sería el perjuicio que se busca evitar a los donantes suponiendo la voluntariedad de tal donación.

Más atendible podría ser el deseo de proteger al hijo nacido mediante estas técnicas y a los llamados receptores de estas prácticas, quizá pensando en evitar que éstos se pudieran ver sometidos a presiones de cualquier tipo.

Lo primero que diriamos al respecto es que la manera más eficaz de neutralizar este tipo de ataques es, precisamente, la transparencia, la publicidad sobre el hecho en sí. Pero, centrándonos en la situación del hijo, podemos comprobar que, en principio, como cualquier otro nacido, los generados mediante la reproducción asistida no participan en la negociación o acuerdo sobre su generación. Su realidad es compleja. Que el Derecho quiera simplificarla artificialmente no nos parece una solución válida. Hay que afrontar la situación de profundo cambio que se ha operado. Intentar mantener los mismos conceptos y las mismas estructuras familiares a pesar de estos cambios no dará resultados satisfactorios.

En nuestra opinión el hijo tiene derecho a conocer su origen biológico y ello no puede garantizarse sino desde el reconocimiento jurídico de la existencia e identidad de los posibles donantes y la consiguiente posibilidad del nacido de conocer, al menos al llegar a su mayoría de edad, su origen y la identidad y rasgos básicos de aquellos que contribuyeron a su generación. No deberia el Derecho frustrar tal posibilidad.

El temor, por otro lado, a que la posibilidad de identificar a los donantes ponga en peligro los derechos de los padres legalmente determinados es, a nuestro juicio, inoperante en este caso a efectos jurídicos. En primer lugar ese temor no tiene por qué responder a un riesgo real. Si las relaciones entre el nacido y los que asumieron la condición de padres es sólida seguirá siéndolo aún con el conocimiento de su origen, y si no lo fuera, no hay que culpar de ello a personas o circunstancias ajenas.

Diríamos, en resumen, que consideramos imprescindible regular el reconocimiento jurídico de todos los sujetos que participen en la generación, aunque pueda discutirse algo más sobre la asignación concreta de derechos y obligaciones e, incluso, sobre la asignación de la condición de padre y madre, sin olvidar la posibilidad de que el hijo conozca, llegado su momento, tanto el modo como fue generado como los posibles donantes que intervinieron en el proceso.

Constitucionalmente, además, es muy discutible que a los donantes se les pudiera excluir del proceso de reproducción hasta el punto de reducirlos a una mera ficha de un archivo, en el mejor de los casos. Para llegar a esta situación habria que haber concluido que ellos, los donantes, no son padres ni madres y para llegar a esa conclusión deberiamos dar 
un nuevo contenido a estos términos. De lo contrario, se produciria un fraude semántico de importantes consecuencias jurídicas, pues, .como ya hemos dicho antes, no cabe dudar que, actualmente, nuestro Derecho cuando trata del padre y de la madre, lo hace, salvo excepciones muy concretamente reguladas, para referirse a los que contribuyeron con su aporte genético a la creación de un nuevo individuo.

Si hasta ahora padre y madre eran los sujetos que generaban biológicamente (salvo las excepciones mencionadas, en concreto, la regulación de la adopción) deberian modificarse, o bien los términos o bien los contenidos, para que terminaran siendo padres los que ahora consideramos no-padres, al menos en un sentido pleno. De no producirse este ajuste entre significantes y significados asistiríamos inevitablemente a un proceso de manipulación semántica de amplias repercusiones juridicas y sociales.

Cuando nuestro texto constitucional afirma que los poderes públicos están obligados a proteger al hijo, con independencia de su filiación y a las madres, cualquiera que sea su estado civil (art. 39.2 de la Constitución), parece innegable que en ambos supuestos está contemplando la filiación biológica de forma, si no absoluta sí muy principal.

Algo parecido sucede con la asignación de obligaciones a los padres que la propia Constitución recoge (art. 39.3). Los constituyentes sin duda pensaban en la conveniencia de constatar la filiación a efectos principalmente de la asignación de obligaciones asistenciales. De ahí que a los padres les corresponda atender a los hijos habidos dentro o fuera del matrimonio (art. 39.3). Es más, en un interpretación literal del texto constitucional, demasiado estricta a mi juicio, podría afirmarse que el término habidos se refiere a generados biológicamente dentro o fuera del matrimonio, interpretación que nos llevaría a reconocer la obligación de los padres sólo para con los hijos generados biológicamente. Los hijos adoptados recibirian dicha protección por el acto legal del reconocimiento el cual lleva implícito la determinación de los derechos y obligaciones inherentes a dicha situación. No creemos, sin embargo que esta interpretación sea la más conveniente, aunque sí avala nuestra afirmación en el sentido de considerar que nuestro texto constitucional contempla la figura del padre y de la madre como generadores biológicos del hijo y que, por ello, les asigna su cuidado y atención. Este es, a nuestro juicio, el principio recogido constitucionalmente. De ahi que consideremos discutible que se pueda, sin más, eliminar la realidad biológica de la relación de filiación como fórmula general para las nuevas técnicas de reproducción asistida.

Según lo que acabamos de decir, la pregunta es la de si es posible, por ley ordinaria, modificar el contenido de un término constitucional como es el de padres o, incluso, el de madre, recogidos en la Constitución con un determinado contenido, sin que tal acción no quiebre en parte el edificio conceptual que la Constitución en este punto asume. En nuestra opinión tal cosa supondría, en una interpretación no demasiado exigente, al menos 
una mutación constitucional. Por ello consideramos que el reconocimiento de la pluralidad de sujetos intervinientes en un proceso de reproducción asistida es necesario y coherente con los postulados defendidos por nuestro texto constitucional.

\section{Reproducción asistida y donación de gametos}

Veamos ahora, más detenidamente, los contornos de la donación de gametos, de la que, sin embargo, algo hemos dicho ya. Nuestro texto constitucional no ofrece criterio alguno al respecto según lo que ya antes hemos mencionado, aunque sí es prolijo en el reconocimiento de la libertad, de la igualdad y de la dignidad de la persona humana. Serán estos parámetros los que nos servirán para intentar una delimitación de los requisitos que serian precisos respecto a la donación de gametos y que tendieran a garantizar precisamente los derechos y libertades fundamentales.

\subsection{Voluntariedad}

Un primer requisito de la donación de gametos es la voluntariedad. Garantizar que los donantes sean absolutamente voluntarios y que conozcan exhaustivamente los detalles y consecuencias de su donación nos parece totalmente necesario.

El carácter de este tipo de donación aconseja, como se menciona en la Proposición de Ley sobre nuevas técnicas de reproducción asistida ${ }^{17}$ que sea realizada sólo por personas con capacidad suficiente para decidir libremente sobre ella. Con este criterio que creemos preferible no deberian ser donantes los incapaces, los deficientes mentales, y los menores.

\subsection{Donación: acto personalísimo}

La donación de gametos es un acto, en nuestra opinión, de carácter personalísimo y cuya responsabilidad atañe exclusivamente a aquel que la realiza. Por ello, expresada su voluntad de llevarla a cabo (voluntad formada con las garantías necesarias para que responda realmente a la realidad sentida por el sujeto en cuanto a forma y fondo), no cabe hacer intervenir en dicha decisión a ninguna otra persona ${ }^{18}$.

17 Art. $5 .^{\circ} 6$ de la Proposición de Ley $122 / 000062$ de Técnicas de reproducción asistida.

18 La Proposición de Ley $122 / 000062$ sobre nuevas Técnicas de reproducción asistida, afirma que será necesaria la autorización del cónyuge o compañero estable de un donante para que éste lleve a cabo dicha donación, art. $5 .^{\circ} 9$. 
No compartimos la opinión de que los donantes casados o aquellos que mantengan pareja estable deban conseguir la autorización de su pareja para realizar tal donación. Jurídicamente no es preciso. Cosa distinta es que el conocimiento de este hecho por parte del otro miembro de la pareja pueda eventualmente dar lugar a la ruptura de ella si es una pareja de hecho o a una separación o divorcio si se trata de un matrimonio. En este sentido seria más sensato prever una nueva causa de separación y divorcio que solicitar, contra la lógica jurídica, la autorización para realizar la donación a una persona que no tiene derechos en sentido jurídico sobre el cuerpo de aquella que realiza la donación. Recordemos que nuestro Código Civil establece que la infidelidad conyugal podrá ser motivo de separación o divorcio, facultad que le asiste al cónyuge no infiel ${ }^{19}$. La donación de gametos no puede compararse a los supuestos de infidelidad, salvo en que de ella puede acontecer el nacimiento de un niño, cosa que también puede suceder en los supuestos de infidelidad conyugal.

En el supuesto de nacimiento de un hijo extramatrimonial o extrapareja estable, al compañero de aquel que generó fuera de esa unión no le queda más solución que la tolerancia o la separación. Igual solución debería darse en el caso de las donaciones que generaran un nacimiento.

\subsection{El secreto de la donación}

La opinión generalizada sobre este punto es que debe garantizarse el secreto sobre la identidad del donante e, incluso, sobre las circunstancias que rodeen el nacimiento de un nuevo sujeto mediante estas nuevas técnicas de reproducción asistida ${ }^{20}$.

Hay varios argumentos en favor de mantener y proteger el secreto de la donación de gametos, algunos ya expuestos en este trabajo. Siguiendo lo que ya dijimos al tratar del necesario reconocimiento jurídico de los sujetos intervinientes en los procesos de generación asistida con donantes, la donación de esperma y de ovocitos, en su caso, debe realizarse de forma que al hijo así nacido le conste, por un lado, que fue generado mediante estas técnicas y por otro lado, la identidad de los que aportaron algún elemento biológico al proceso.

La base jurídico-constitucional que, a nuestro juicio, sostiene esta afirmación y sin perjuicio de lo ya dicho anteriormente, gira en torno a los siguientes aspectos.

19 El artículo 82.1.a del Código Civil.

- En opinión de M. P. GaRcia Rubio, también cabria entender vulnerada el deber conyugal de respeto mutuo; «La experiencia jurídica italiana en materia de fecundación asistida». Comunicación en el Congreso Hispanoamericano de Familia, Cáceres, 16 al 20 de octubre de 1987.

20 Este es el criterio, erróneo a nuestro juicio, que sigue la Proposición de Ley $122 / 000062$ en su art. 5.10. 
La Constitución ha reconocido la posibilidad de investigación de la paternidad (art. 39.3), posibilidad que la ley civil ha ampliado a la investigación de la maternidad (art. 127 del Código civil). En sentido estricto, pues, resultaría inconstitucional que los poderes públicos regularan a favor del secreto de los donantes de esperma, mientras que vulneraría la ley civil únicamente el mismo supuesto respecto al gameto femenino. No creemos, con todo, que sea ésta la interpretación más aconsejable. El hecho de que la Constitución no introduzca la investigación de la maternidad junto a la de la paternidad no se debe sino a una falta de previsión de los constituyentes que, una vez más, se dejaron llevar de una cierta inercia histórica en este punto. Inercia histórica que ha configurado como un logro, cierto sin duda, en materia de derecho y libertades, la investigación de la paternidad como superación de la situación de cierta inmunidad de que gozaban los hombres respecto a sus obligaciones en cuanto a la procreación, en especial, a la procreación fuera del matrimonio, lo que no parecia ser el supuesto común de las madres.

De circunscribir actualmente, y dentro del contexto de las nuevas técnicas de reproducción asistida, el derecho del hijo a conocer su origen biológico exclusivamente respecto del progenitor masculino dejariamos un importante vacio en este punto y ello exclusivamente por seguir literalmente la redacción constitucional que si bien sólo cita la posibilidad de investigación de la paternidad no impide que tal investigación se extienda a la maternidad, como así lo ha entendido la ley civil.

De lo dicho podríamos concluir que la Constitución, con mejor o peor fortuna en su redacción, reconoce en el artículo 39.2 el derecho del hijo a conocer quiénes fueron sus progenitores. Se impone una interpretación amplia del término paternidad que incluya también la maternidad, lo mismo que, tanto en el lenguaje coloquial como en el jurídico, cuando se utiliza el término padres se entiende incluida también, sin asomo de duda, la madre. De este modo la redacción constitucional seria más acorde con la nueva realidad.

Las técnicas de reproducción asistida refuerzan la conveniencia de nuestra interpretación. Mediante estas técnicas la identidad del padre es absolutamente cierta y única, mientras que es la identidad de la madre la que puede encontrarse en entredicho. Efectivamente, siendo la aportación de la mujer la que únicamente puede dividirse es en su caso en el único en el que puede plantearse, siempre en términos biológicos, cuál de las posibles aportaciones otorga a la mujer la condición de madre 0 , si más bien, sería conveniente el reconocimiento de tal pluralidad de sujetos concurrentes. Con las nuevas formas de reproducción asistida, la identidad de los generantes pierde cualquier atisbo de duda.

Si el principio constitucional es favorable a la constatación de la identidad biológica de los padres y a que el nacido conozca su origen, este mismo principio debe servirnos para afirmar nuevamente que los poderes públicos no están habilitados para legislar en contra del mismo y en favor 
del secreto en las donaciones. No parece tener mucho sentido que mientras la Constitución propugna la posibilidad de identificar al padre biológico (pues la investigación de la paternidad legal es una contradicción en los términos), los poderes públicos se encarguen de ocultar precisamente a estas personas que generan biológicamente.

Por lo que hemos expuesto, nuestra opinión es contraria a la implantación del secreto en las donaciones de gametos. En este caso, el derecho a la intimidad, regulado en el artículo 18 de la Constitución, no puede amparar situaciones que impidan el ejercicio de otros derechos también reconocidos constitucionalmente. En este sentido nos parecen inadecuadas opiniones como la de C. PEÑALOSA LOPEZ-PIN ${ }^{21}$ cuando propone, para evitar precisamente esta publicidad, que en los casos de inseminación artificial heteróloga (con donante) se utilice «de forma combinada semen del marido de la mujer inseminada y semen del donante. Con este procedimiento, y potenciando al máximo la compatibilidad entre ambos, puede ser difícil discernir cuál es el padre biológico». Con lo que parecen acabar, para esta autora, todos los problemas que puedan plantearse, mediante la creación de una situación de confusión tal que impida conocer la realidad ${ }^{22}$.

\subsection{El carácter comercial de la donación de gametos}

Respecto a si estas prácticas deben tener carácter comercial o no, diremos que, de hecho, ello dependerá, como tantas otras cosas, de la oferta y la demanda que exista de estos elementos, aunque el Derecho deberá tomar su propia postura al respecto. Si media precio, dejarán, obviamente, de ser donaciones para convertirse en aspectos insertos en el tráfico comercial.

En nuestra opinión estas prácticas deberian quedar fuera del comercio. En este mismo sentido, la Comisión especial de estudio de la fecundación in vitro y la inseminación artificial humanas del Congreso de los Diputados ${ }^{23}$, opina que la realización de estas técnicas no debe mover a operaciones mercantiles entre los donantes y los receptores aunque reconoce, contra nuestro criterio, alguna excepción en determinadas circunstancias. Y, siguiendo las recomendaciones de la Comisión especial del Congreso el artículo 5.1 de la Proposición de Ley sobre nuevas técnicas de reproducción asistida, ya mencionada anteriormente, prohibe el carácter lucrativo de la donación de gametos, aunque no cierta compensación por los gastos ocasionados al donante.

${ }^{21}$ C. PENALOSA LOPEZ-PIN, “Observaciones médicas y juridicas de la inseminación artificial humanas", Boletin del l. Colegio de Abogados de Madrid, n. ${ }^{\circ} .4 / 1986$, pág. 23.

${ }^{22}$ Con buen criterio, a nuestro juicio, la Proposición de Ley 122/000062, en su art. 4.1, ha prohibido la utilización combinada de semen de donante.

${ }^{23}$ Comisión especial de estudio de la fecundación in vitro y la inseminación artificial humanas. Congreso de los Diputados, Madrid, 1987, pág. 74. 


\subsection{La revocabilidad de la donación de gametos}

Los primeros intentos de dotar de regulación jurídica las prácticas de reproducción asistida en nuestro país, declaran la irrevocabilidad de la donación ${ }^{24}$. En nuestra opinión la donación debe ser revocable en la medida en que el material biológico donado no haya sido utilizado, y debería llevar aparejada la destrucción de los gametos donados siempre y cuando, insistimos, se encuentren todavía en el mismo estado en el que fueron donados, como esperma o como ovocitos. Si este material ha sido utilizado y con él generados nuevos individuos, aunque éstos se encuentren en estado embrionario, la donación debe ser considerada irrevocable. Se trata, pues, de considerar que existe un plazo para la revocabilidad, término variable en tanto en cuanto su extensión viene delimitada por el momento de la utilización del material donado. Este nuevo criterio avala, junto con otros expuestos en este trabajo, la transparencia que, en nuestra opinión, debe rodear el proceso de donación de gametos y las garantias que deben otorgarse a los donantes para llevarla a cabo. Otra cosa no sería acorde ni con el respeto a la libertad individual ni con las garantias precisas para la formación de la voluntad de la donación.

\section{LA GESTACIÓN DE SUSTITUCIÓN: LAS MADRES DE ALQUILER}

\section{Concepto}

La llamada maternidad subrogada o gestación de sustitución es un aspecto surgido como consecuencia de las nuevas técnicas de reproducción asistida, especialmente por la posibilidad de la fecundación in vitro, ya que esta práctica combinada con la gestación por sustitución permite a una mujer que no pueda llevar a término un embarazo tener un hijo genéticamente suyo por la fecundación de su propio ovocito y semen de su compañero o donado en laboratorio.

Por tanto, las Ilamadas madres de alquiler son mujeres que aceptan, mediante precio o no, llevar a término un embarazo que, normalmente, se ha generado mediante esperma del varón que aparecerá como padre y un ovocito de la mujer que aparecerá como madre, para, producido el parto, entregar el hijo a las personas que lo encargaron y asumieron el pago de la cantidad fijada o los gastos ocasionados por el embarazo y el parto.

${ }^{24}$ Proposición de Ley $122 / 000062$, de Técnicas de reproducción asistida, art. $5 .^{\circ} 4$. 
El citado es el caso más común de alquiler de útero pero no el único posible, pues se podrian producir algunas variantes, por ejemplo, si el embarazo se consiguiera mediante inseminación artificial a partir del esperma del varón que aparecerá finalmente como padre del nacido, siendo, en este caso, el ovocito también de la mujer gestante. En mi opinión, este es un supuesto menos complicado a efectos juridicos ya que el hijo nacido lo será del que figure como padre y que fue quien donó el esperma y de la mujer gestante, ya que la posible madre y compañera del donante o receptor en este caso no tendría ningún vínculo biológico con el nacido en que basarse para reclamar ningún tipo de maternidad. Como veremos, estos supuestos suelen apoyarse en contratos cuyo valor jurídico es discutible en nuestra opinión.

O también, llegado a cierto punto extremo, podría conseguirse un embarazo a partir de donantes de esperma y ovocitos, con lo que el hijo nacido no tendría ninguna relación biológica con los receptores o personas que asumen la paternidad y maternidad legal, que bien pudieran ser ambos estériles. Esta fórmula dista poco de las prácticas de pactar una adopción antes de producirse el nacimiento. La única diferencia sería que, en este último caso, el origen del embarazo no suele ser premeditado ${ }^{25}$.

\section{La maternidad por contrato}

En nuestra opinión, la maternidad subrogada presenta los problemas más difíciles de resolver en este campo. Quizá, como se afirma, tenga «analogías, de forma suavizada pero cierta, con la venta de niños que ha sido un estigma social combatido siempre con la máxima dureza» ${ }^{26}$. Este tipo de pactos se suelen documentar en un contrato entre las partes, contrato que, a nuestro juicio, no tiene validez en nuestro vigente Ordenamiento jurídico, entre otros motivos que expondremos porque los negocios jurídicos relativos al Derecho de Familia están sustraídos a la autonomía de la voluntad de las partes, por el interés público, por los fuertes imperativos éticos y la función social que los preside, los derechos subjetivos de este tipo de relaciones quedan sustraídos a la libre disponibilidad de las partes, de tal manera que las renuncias, transacciones, etc., quedan como regla general prohibidas en las relaciones de estado familiar ${ }^{27}$.

${ }^{25}$ La Disposición Adicional segunda de la Proposición de Ley 122/000062 prohibe esta práctica, adecuadamente según mi opinión.

${ }^{26}$ C. PEÑAlosa LóPEZ-PIN, «Observaciones médicas y juridicas acerca de la inseminación artificial humanas", Boletín del I. Colegio de Abogados de Madrid, núm. 4/1986, pág. 24.

27 «- Informe de la Comisión especial de estudio de la fecundación in vitro y la inseminación artificial humanas". Congreso de los Diputados, Madrid, 1987, pág. 90.

- En este mismo sentido se ha pronunciado el "Informe Warnock» (Reino Unido); y el "Comité National dÉthique" (Francia). 
Diremos, en principio, que sin la existencia de pacto expreso no es ni siquiera discutible que el hijo nacido mediante estas prácticas deberá recibir el mismo trato que, finalmente, se de a los casos de reproducción asistida mediante donante. La mujer gestante será la madre gestativa y la mujer que donó el ovocito, en su caso, será la madre genética. El hombre que donó el esperma será el padre genético.

Pero, los problemas estrictamente jurídicos se plantean porque este tipo de prácticas han venido apoyándose, alli donde se han producido (lnglaterra y Estados Unidos principalmente), en un documento o contrato de maternidad por alquiler. La pregunta es, por tanto, qué validez jurídica pueden tener este tipo de pactos expresos como cobertura legal del hecho concreto de una gestación por encargo.

Entendemos que nuestro Ordenamiento jurídico vertebrado por el vigente texto constitucional, impide contratar la gestación y entrega de un recién nacido ya que el niño ni es una cosa ni es objeto de comercio. Más aún, ni siquiera podria considerarse al embrión como una cosa en sentido técnico, por lo que consideramos que no debería reconocerse una suerte de derecho de propiedad sobre el embrión. El embrión no puede ser algo susceptible de apropiación ni de libre circulación ${ }^{28}$. En ningún caso el embrión o el recién nadido podrían ser objeto válido de un contrato que implicara su entrega, y, especialmente, su generación para llevar a cabo tal entrega. Dificilmente podríamos argumentar de modo favorable a la posibilidad de transferir un recién nacido o pactar su gestación previo encargo. No es posible ver altruismo o desinterés en ello. Los vigentes textos constitucionales no recogen, por innecesario, el derecho de todos a no ser objeto directo de ningún contrato entre dos o más partes, ni a que sobre su persona recaigan derechos y obligaciones derivados de contrato en los que ellos mismos no son parte voluntaria y consciente. Tal cosa no seria compatible ni con un régimen de libertades ni con el necesario respeto a la dignidad humana reconocida en la Constitución. Gestar por cuenta ajena, entregar el fruto de la concepción como cumplimiento de una obligación de carácter jurídico no difiere gran cosa del poder que poseía el pater familias en la sociedad romana sobre sus esclavos y los descendientes de éstos.

Las cláusulas de este tipo de pactos que lógicamente obligarían a la madre gestante a renunciar a todos sus derechos sobre el recién nacido serian, a nuestro juicio, contrarias a las leyes y al concepto de orden público que sirve de criterio interpretativo en nuestro Derecho. Pero, lo que es aún más determinante, en cualquier caso la madre gestante es madre, al menos en este aspecto, del recién nacido y, siendo así, la renuncia pura y simple a sus derechos y obligaciones nos plantea la misma interrogante que ya

28 Este es el sentido que informa en parte la redacción de la Proposición de Ley $122 / 000061$ de donación y utilización de embriones y fetos humanos o de sus células, tejidos u órganos, presentada en el Congreso de los Diputados por el Grupo Parlamentario Socialista. 
exponiamos al tratar del reconocimiento jurídico de los donantes, pues no cabe duda que cuando la Constitución tutela la figura de la madre (art. 39.2) - encarga a los padres la asistencia de todo orden a sus hijos habidos dentro o fuera del matrimonio (art. 39.3) está contemplando preferentemente la relación biológica. Por otra parte, la ley civil determina (art. 110 del Código civil) que compete a los padres la asistencia al hijo aún no ostentando la patria potestad, lo que confirma nuestra opinión acerca del reconocimiento de la relación biológica en nuestro Derecho. Por último el Código penal (arts. 488 y 489), sanciona el abandono de los menores. Cabria preguntarse si, en los supuestos de maternidad subrogada, con entrega posterior del hijo, no existe un abandono del recién nacido y consiguiente incumplimiento de los deberes jurídicos inherentes a la procreación biológica, al menos, en el aspecto gestativo. Si la madre gestante también aportó la carga genética, el traslado del hijo a otra mujer (por ejemplo, la esposa o compañera del donante del semen) o se formaliza como una adopción o se trataria del supuesto jurídico de suposición de parto.

Respecto al varón, si donó el esperma es el padre genético tanto si asume las obligaciones legales como si no lo hace. $Y$, si no donó el esperma para la generación del nuevo sujeto, ningún vínculo le une al nacido, por tanto, si quiere aparecer como padre deberá llevarse a cabo su reconocimiento a efectos legales, como si se tratara de una adopción. Consideramos totalmente inadecuado que pueda figurar como padre, sin más requisito legal, el marido de la mujer receptora de estas prácticas que, en este caso, no sería la madre gestante sino, quizá, la mujer que donó el ovocito. No pueden considerarse en estos casos válidas las presunciones que puedan servir para los supuestos de reproducción natural. Como ya hemos dicho antes en este mismo estudio, la reproducción asistida da certeza sobre la identidad de los progenitores biológicos, por lo tanto es inadmisible que la ley ponga confusión donde no la hay.

Con lo expuesto queriamos poner de manifiesto hasta qué punto pueden resultar forzadas las normas jurídicas en su aplicación a las nuevas formas de reproducción asistida y cómo para este tipo de problemas y situaciones se deben buscar soluciones nuevas en el campo jurídico, llegando, incluso, a acuñar una nueva terminología que pueda corresponderse con la nueva realidad.

A todos los aspectos negativos que sobre la gestación de alquiler hemos expuesto, debemos agregar los que se derivarian de la utilización del cuerpo de la mujer como mero recinto gestador. Sin duda, esta práctica puede constituirse en una forma de manipulación del cuerpo femenino (a la que la situación desfavorable de la mujer en el mercado de trabajo puede contribuir), inadmisible en una sociedad democrática que posiblemente desencadenaria un abuso y una comercialización a todas luces condenables y que llevarían a la mujer a una situación muy difícil. 
Este tipo de práctica podria llevar a la creación de un cuerpo de gestadoras remuneradas. Negándoles validez jurídica se lograría un cierto efecto disuasor porque los riesgos son muy grandes y las garantías para la libertad de la mujer muy pequeñas. La esterilidad, por penosa que pueda resultar a las personas que la sufren no es motivo suficiente para estas prácticas. Las nuevas formas de reproducción asistida pueden dar solución a problemas concretos y profundizar en el derecho a la procreación de toda persona y por ello hay que considerarlas positivas, pero no existe, como ya dijimos, un derecho absoluto a tener hijos, a reproducirse. Por eso creemos que la prohibición de la gestación por sustitución es otro límite, junto a los que ya citamos, del derecho de toda persona a reproducirse. De forma semejante concluyó en su informe la Comisión de estudio de la inseminación artificial y la fecundación in vitro, manifestando que no había a su juicio razones suficientes para regular jurídicamente estas prácticas ya que "las implicaciones son, individual, ética, social y legalmente demasiado graves y complejas, máxime si los riesgos a correr se producen para satisfacer no un hecho de urgencia vital, sino un deseo maternal muy loable, pero que no puede considerarse un derecho absoluto a satisfacer desde perspectivas unilaterales. Por ello - agregaba la Comisión en sus conclusiones - recomendamos que la gestación de sustitución debe prohibirse actualmente en cualquier circunstancia, y que también deben prohibirse las actuaciones que la propicien. $Y$ por 10 mismo, que las personas que de un modo $u$ otro, de forma contratada o no, intervengan en ella, incluidos los equipos médicos y los Centros en los que llegare a realizarse, sean sancionados severamente. En cualquier caso, los hijos que llegaren a nacer por esta forma de gestación a considerar ilegal, lo serán legalmente de la madre gestante ${ }^{29}$.

Por nuestra parte, coincidimos en que, efectivamente, no parecen existir razones suficientes, ni de índole sentimental ni de índole médicocientífica, para justificar estas prácticas que bien podrian desencadenar fenómenos imprevisibles y que, a nuestro juicio, no favorecerian en nada la situación de la mujer en la sociedad. Pero, respecto al futuro, no estamos tan seguros de que baste con la ilegalización de estas prácticas para hacerlas desaparecer del mundo. Desafortunadamente todo dependerá de los intereses en juego. ¿Podría beneficiar a alguien la asignación de la reproducción humana a unas gestadoras que asumieran en exclusividad este trabajo? ¿Podría eso beneficiar la producción mundial? ¿Qué sucedería con la actual división sexual del trabajo? Estas y otras preguntas despiertan; sin duda, profunda inquietud. Confesamos no tener respuesta válida a ellas.

29 Igual criterio sigue la Proposición de Ley 122/000062, en la Disposición Adicional Segunda, basándose probablemente en el Informe de la Comisión especial de estudio de la fecundación in vitro y la inseminación artificial humanas, Congreso de los Diputados, ob. cit., pág. 119. 
También, en mi opinión, las gestaciones de alquiler son contrarias a la dignidad de la mujer, difícilmente compatibles, además, con los postulados de una sociedad democrática, por lo que tienen de manipulación, encargo y pacto sobre la creación para terceros de un ser humano.

Cuando analizamos estas prácticas no podemos dejar de pensar si no perderá la mujer en ellas parte de la dignidad y los derechos que con tanta dificultad ha conseguido a lo largo de cientos de años.

La lucha de las mujeres porque su cuerpo no fuera considerado como una mera máquina reproductora carece de sentido ante la práctica de la maternidad subrogada. Pero los atentados contra la dignidad de la mujer son tantos y la vulneración de sus derechos son tan frecuentes en su entorno que no nos atrevemos a afirmar que la ilegalización de estas prácticas pueda protegerla absolutamente de manipulaciones y presiones. La evolución de la propia sociedad y el posible beneficio que de esta técnica pueda conseguirse serán determinantes en este punto. Como dijo J. ORTEGA Y GASSET ${ }^{30}$, "a nadie le es dado elegir el mundo en que se vive; es siempre éste, éste de ahora... La vida nos es disparada a quemarropa".

\section{LA GESTACIÓN ASISTIDA EN LA MUJER SOLA.}

En la mayoría de los estudios realizados acerca de las nuevas técnicas de reproducción humana se plantea el problema de si se debe acceder a que la mujer sola, sin pareja, pueda tener una gestación asistida.

Por lo que ya hemos expuesto hasta el momento en este trabajo, nuestra opinión es favorable a que las mujeres solas puedan acceder libremente, en igualdad de condiciones que las parejas, a estas técnicas de reproducción humana.

Según la Comisión especial creada en el Congreso de los Diputados, no cabe afirmar que en todos los casos sea favorable a los hijos su permanencia en el grupo familiar, presuponiendo una estabilidad de la que no siempre goza éste, ya que, en ocasiones, salen beneficiados en su armonia vital al separarse los padres y recaer la responsabilidad de cuidarlos y educarlos en uno solo de aquéllos. Por otra parte, un modelo familiar legalizado y presente es aquel en el que una persona adulta, hombre o mujer, ha recurrido a la adopción de un hijo o hijos. Asimismo, se ha descrito la valoración que se va produciendo de la maternidad y la paternidad, interpretadas actualmente con una visión más amplia, y en las que se aúnan y complementan factores genéticos, de gestación, de deseo y edu-

30 J. Ortega y Gasset, El hombre y la gente, Alianza Ed., Madrid, 1980, pág. 49. 
cacionales $^{31}$. Prosigue la Comisión diciendo que no puede negarse a priori la bondad y validez de la familia constituida por un solo adulto, como lo prueba el hecho legal de la familia constituida por personas solas que adoptan hijos; la mujer sola que va a ser madre biológica, cuenta con el importante hecho de una maternidad de deseo, educacional y legal. $Y$, por otro lado, en estos supuestos la gestación de la mujer sola no genera conflictos entre partes, como se podian producir en los supuestos de gestación de alquiler. Concluye la Comisión que "la recomendación es que sea posible legalmente la gestación en la mujer sola» ${ }^{32}$, aunque establece algunas condiciones como que se acredite la capacidad para educar y sustentar al hijo ${ }^{33}$.

No todas las opiniones, por otro lado, son favorables a la maternidad en solitario que, por nuestra parte, defendemos sin reservas. Así por ejemplo, entre las conclusiones obtenidas por el Grupo de Trabajo constituido en la Dirección General de los Registros y del Notariado, se antepone un discutible principio de bienestar del hijo que se basaria en su derecho a nacer en condiciones apropiadas al desarrollo de su personalidad (condiciones que se dan exclusivamente, al parecer, dentro del matrimonio y la familia tradicional, sin que se aporten mayores argumentos al respecto) en detrimento de la libertad de la mujer para decidir su maternidad. Se afirma, en estas conclusiones, que clos hijos tienen fines propios y no deben ser instrumentalizados para satisfacción de los sentimentalismos de una mujer solitaria. No cabe el argumento de que una soltera hoy pueda adoptar, pues no es lo mismo proteger, con el remedio posible, a un ser ya existente que provocar, con la colaboración oficial, su venida al mundo en condiciones socialmente insuficientes" ${ }^{34}$. Como en otras ocasiones, tendríamos que preguntarnos de dónde proviene tal insuficiencia.

Pero, por si lo dicho no fuera bastante, se prosigue afirmando por parte de M. PEÑA BERNALDO DE QUIROS, vocal de este Grupo de Trabajo, que «si bien es lógico que el Estado respete la libertad de tener hijos en el estado civil que sea, no ocurre lo mismo cuando los hijos sólo pueden venir al mundo con una colaboración oficial o cuasi oficial (la de establecimientos sanitarios autorizados). Lo menos que se puede pedir a las de-

31 Comisión especial de estudio de la fecundación in vitro y la inseminación artificial humanas, Congreso de los Diputados, ob. cit., págs. 41 y 42.

${ }_{32}$ Comisión especial de estudio de la fecundación in vitro y la inseminación artificial humanas, Congreso de los Diputados, ob. cit., pág. 93.

${ }_{33}$ Nuevamente la Proposición de Ley $122 / 000062$ aporta un criterio, a nuestro juicio válido en este punto, al permitir el acceso de las mujeres solas no estériles a la reproducción asistida, aunque determina que en estos casos las mujeres deberán asumir el coste económico del proceso, con lo que de alguna manera el reconocimiento del derecho a la reproducción queda limitado por razón económica, cosa que no consideramos ajustada a las pautas constitucionales.

${ }^{34}$ Problemas civiles que plantea la inseminación artificial y la fecundación in vitro. Ministerio de Jusicia, ob. cit., pág. 10. 
cisiones oficiales es que sean racionales" ${ }^{35}$. Por todo lo dicho no podemos estimar adecuado este planteamiento.

La Constitución nos ofrece argumentos suficientes para rechazar las opiniones citadas en último lugar. La maternidad está constitucionalmente protegida, no sólo reconocida como una facultad de la mujer, sino que los poderes públicos asumen su protección y lo hacen con independencia del estado civil de la madre (artículo 39.2). Por si este argumento no fuera suficiente, el artículo 9.2 declara la obligación de los poderes públicos en orden a la consecución de la igualdad y libertad reales y efectivas de todos los individuos y, por su parte, el artículo 14 proclama el principio de igualdad ante la ley de todos los españoles. El estado civil es una condición personal o social que, en ningún caso, puede emplearse para restringir los derechos de las personas. Si nadie puede ser discriminado por estar casado o viudo, tampoco puede serlo por su condición de soltero. Si el Estado permite la inseminación artificial de las mujeres casadas $y$, todavía más, de las solteras con pareja estable acreditada ${ }^{36}$, no hay argumentos jurídicoconstitucionales que expliquen la exclusión de la mujer sola.

No olvidemos, por último, que la Convención Europea de Derechos Humanos informa del derecho a la maternidad de la mujer sola, de las parejas lesbianas y a la paternidad de las parejas homosexuales ${ }^{37}$.

\section{FINAL}

Se repite con frecuencia que el Derecho no está obligado a reconocer y regular todo lo que es posible. Basta, diriamos nosotros, con que regule aquello que favorezca la convivencia, profundice en la libertad y la igualdad de todos y permita un desarrollo más armónico y equilibrado de la organización social.

Al regular las nuevas formas de reproducción asistida el Derecho debe ser especialmente cauteloso. Se mueve en terrenos muy cercanos a esa esfera íntima de la persona en la que ésta debe ser única gobernante. Rozará acaso con sentimientos y motivaciones incomprensibles a cualquier razonamiento juridico y tendrá que detener su paso ante la puerta de la dignidad personal. Ese es el gran reto y está casi todo por hacer en este campo.

${ }^{35}$ Problemas civiles que plantea la inseminación artificial y la fecundación in vitro. Ministerio de Justicia, ob. cit., pág. 10.

36 Así se previene en la Proposición de Ley 122/000062, art. 7.

${ }_{37}$ Según deja constancia la Comisión especial de estudio de la fecundación in vitro y la inseminación artificial humanas. Congreso de los Diputados, ob. cit., pág. 41. 